\title{
The effectiveness of hyperbaric oxygen in patients with idiopathic sudden sensorineural hearing loss: a systematic review
}

\author{
Burak Eryigit $^{1}$ (1) $\cdot$ Fuat Ziylan $^{2} \cdot{\text { Furkan } \text { Yaz }^{1} \cdot \text { Hans G. X. M. Thomeer }}^{1,3}$
}

Received: 22 July 2018 / Accepted: 5 October 2018 / Published online: 15 October 2018

(c) The Author(s) 2018

\begin{abstract}
Objective To evaluate the effectiveness of hyperbaric oxygen in the treatment of patients with idiopathic sudden sensorineural hearing loss (ISSHL).

Data sources An Embase, MEDLINE and Cochrane search were utilised to identify various clinical trials on the treatment of ISSHL. Studies that were published between 2002 and 2018 and written in the English, Dutch or German language were included. Search terms included synonyms for idiopathic sudden hearing loss.

Data synthesis A total of 16 articles were identified regarding hyperbaric oxygen therapy. All patients were evaluated with pure-tone audiometry. A major part of the cases presented with unilateral hearing loss(bilateral hearing loss less than 5\%). In several studies, the average of the mean hearing gain at five contiguous frequencies was significantly higher in the hyperbaric oxygen (HBO) therapy and systemic steroid (SS) group in patients with severe or profound hearing impairment. They recorded a significant treatment effect $(p=0.005)$ of $\mathrm{HBO}+\mathrm{SS}$ therapy on patients with an initial hearing loss of $\geq 81 \mathrm{~dB}$. Conclusions On the whole group of ISSHL patients, no significant difference was demonstrated between the intervention and control group. However, in severe or profound hearing-impaired ISSHL patients, significant benefit was observed in the intervention group. These results likely indicate that adding HBO to steroid therapies might be of benefit in cases of severe and profound hearing impairment.
\end{abstract}

Keywords Hyperbaric oxygen · Sensorineural hearing loss $\cdot$ Corticosteroids

\section{Introduction}

Idiopathic sudden sensorineural hearing loss (ISSHL) may be outlined as hearing impairment over at least $30 \mathrm{~dB}$ on three adjacent frequencies. It develops within an interval of maximum 3 days [1]. The incidence ranges from 5 to 20 per 100,000 cases per year [2]. As it is an idiopathic disease, the etiological factors causing this disease are still uncertain. Although viral diseases and vascular deficiencies of the

Hans G. X. M. Thomeer

H.G.X.M.Thomeer@umcutrecht.nl

1 Department of Otorhinolaryngology and Head and Neck Surgery, University Medical Center Utrecht, Heidelberglaan 100, 3584 CX Utrecht, The Netherlands

2 Department of Otolaryngology-Head and Neck Surgery, Ear \& Hearing, Amsterdam UMC, Vrije Universiteit Amsterdam, De Boelelaan 1117, Amsterdam, The Netherlands

3 Brain Center Rudolf Magnus, Utrecht, The Netherlands cochlea might be causative for ISSHL, definitive evidence is absent [3].

The prognosis of ISSHL is difficult to determine, if we take into consideration the possibility of spontaneous recovery. This phenomenon seems to occur in $29-78 \%$ of patients affected by ISSHL. The shape of the audiogram at onset of the disease may be a predictor of hearing recovery [4].

In clinical practice, systemic steroid therapy (SS) has been the mainstay for ISSHL. More recently, intratympanic steroid (ITS) treatment has emerged and became more popular with otolaryngologists. This is an interesting option due to absence of unfavourable side effects [endocrine problems (i.e., diabetes dysregulation), osteoporosis or weight gain] which are known in the systemic steroid treatment [5].

Hyperbaric oxygen therapy has been commonly used for a long period of time. It was first used in the late 1970s by Goto and Vincey in the treatment of ISSHL [6, 7]. Goto stated that this form of treatment would increase perilymph oxygenation, which is one of the main reasons for utilising this form of treatment with ISSHL patients. Similar results 
were reported by Lamm et al., who showed that HBO therapy would increase the oxygen tension of the perilymphatic fluids and improve the microcirculation of the inner ear [8].

In theory, a combination of treatments might provide a better outcome for patients with ISSHL. Therefore, this systematic review will investigate evidence for a possible effect of HBO treatment on hearing recovery in ISSHL patients.

\section{Materials and methods}

No ethical committee approval was required for this literature review. The systematic review was conducted according to the preferred reporting items for systematic reviews and meta-analyses (PRISMA) statement [9, 10].

\section{Search strategy}

An electronic search in the Cochrane library, PubMed and EMBASE databases was performed on 19-05-2018. These searches were conducted to identify clinical trials on the treatment of idiopathic sudden sensorineural hearing loss. The PICOS structure was utilised to define the research strategy. It was mandatory for the published studies to be written in the English, Dutch or German language and published between 2002 and 2018. The following search terms were applied: sudden sensorineural hearing loss, sudden deafness and idiopathic sudden hearing loss. Restrictive search terms were hyperbaric therapy, oxygen therapy, corticosteroids and dexamethasone. The detailed search strings can be found in Appendix 1. Titles and abstracts were independently screened by two of the authors (B.E. and F.Y.). Then, the full text of the eligible articles was read. Cross-reference check of included articles was conducted to achieve additional relevant articles. The PRISMA flowchart was used [10].

\section{Criteria for inclusion}

Each study had to be a clinical trial that compared the treatment of sudden sensorineural hearing loss with a control group. Intravenous, oral and intratympanic corticosteroid treatment comparing combinations with or without hyperbaric oxygen therapy, were included. Patients with a sensorineural hearing loss equivalent to at least $30 \mathrm{~dB}$ met the inclusion criteria.

\section{Criteria for exclusion}

Several criteria for exclusion were applied: (1) patients who had another cause for their sudden sensorineural hearing loss such as noise, infections or ototoxic medication, (2) conductive hearing impairment, (3) case reports, and comments on articles and reviews, (4) Other languages than English, Dutch or
German, (5) patients receiving therapy after 30 days of onset of ISSHL.

\section{Quality assessment}

After screening of title, abstract and full text, the remaining articles were critically appraised for risk of bias. Quality assessment of eligible studies was assessed according to the risk of bias assessment tool for non-randomized studies (RoBANS) [11].

\section{Data extraction}

Study characteristics and outcome data of included studies were extracted, namely: publication year, study design, participants, type of treatment (oral, intravenous or intratympanic steroids), duration and dosage of treatment, follow-up period and pure-tone average (PTA). The primary outcome was the PTA. The committee of the AAO-NHS, established various guidelines for diagnostic criteria in 1995 [12]. To comply with those guidelines, we maintained subsequent hearing levels at four different frequencies (500, 1000, 2000 and $4000 \mathrm{~Hz}$ ). These frequencies were measured and calculated for every patient individually. Siegel's criteria were utilised to obtain three different categories of improvement. Category I for cases with complete hearing improvement (final hearing better than $25 \mathrm{~dB}$ ), category II indicates moderate hearing improvement ( $>15 \mathrm{~dB}$ gain, final hearing of $25-45 \mathrm{~dB}$ ) and Siegel category III-IV was defined as no hearing improvement $(<15 \mathrm{~dB}$ gain, final hearing poorer than $75 \mathrm{~dB}$ ) (Table 1) [13].

All groups are assessed based upon their hearing level. This hearing impairment has been categorised according to a standard which has been identified by the World Health Organisation (WHO) [14]. No hearing loss has been defined as a hearing level of $26 \mathrm{~dB}$ or lower. $26-60 \mathrm{~dB}$ hearing level has been classified as mild/moderate impairment. Severe impairment is classified as a hearing loss of $61-80 \mathrm{~dB}$, finally a hearing loss of $81 \mathrm{~dB}$ and beyond is graded as profound hearing impairment [14]. The average of the mean hearing gains were calculated and compared within the groups.

\section{Ethical considerations}

Informed consent was obtained from all patients. The participants were given oral information regarding the procedures by their ENT doctors. 
Table 1 Objective outcomes

\begin{tabular}{|c|c|c|c|c|c|c|c|c|}
\hline Intervention & Study & $\begin{array}{l}\text { PTA }(\mathrm{dB})(\mathrm{SD} / \\
\text { IRQ) } \\
\text { (PTA at baseline) } \\
(\Delta \%)\end{array}$ & $\begin{array}{l}\text { PTA level } \\
(\mathrm{kHz})\end{array}$ & $\begin{array}{l}\text { Complete } \\
\text { hearing } \\
\text { improvement } \\
(\%)^{*}\end{array}$ & $\begin{array}{l}\text { Moder- } \\
\text { ate hearing } \\
\text { improvement } \\
(\%)^{*}\end{array}$ & $\begin{array}{l}\text { No hearing } \\
\text { improvement } \\
(\%)^{*}\end{array}$ & $\begin{array}{l}\text { Mean hear- } \\
\text { ing gain }<60 \\
\mathrm{~dB}\end{array}$ & $\begin{array}{l}\text { Mean hear- } \\
\text { ing gain }>61 \\
d B\end{array}$ \\
\hline \multirow[t]{16}{*}{$\begin{array}{l}\text { Corticosteroid } \\
\text { only }\end{array}$} & Cekin & $\begin{array}{l}50.63 \\
(95.85) \\
-48 \%\end{array}$ & $\bullet$ & $11 / 20(55 \%)$ & $4 / 20(20 \%)$ & $5 / 20(25 \%)$ & $\bullet$ & $\bullet$ \\
\hline & Topuz & $\begin{array}{l}53.1 \\
(70.5) \\
-22.8 \%\end{array}$ & $0.5,1,2$ and 4 & $\bullet$ & $\bullet$ & $\bullet$ & $22.33 \pm 9.31$ & $16.18 \pm 9.00$ \\
\hline & Fujimura & $\begin{array}{l}56.0 \pm 2.58 \\
(62.8 \pm 2.2) \\
-10.8 \%\end{array}$ & $0.5,1,2$ and 4 & $16 / 63(25.4 \%)$ & 25/63 (39.7\%) & $22 / 63(34.9 \%)$ & 口 & - \\
\hline & Pezzoli & $\begin{array}{l}56.0 \pm 11.4 \\
\quad(61.0 \pm 20.8) \\
-8.2 \%\end{array}$ & $\begin{array}{l}0.5,1,2,4,6 \\
\quad \text { and } 8\end{array}$ & $0 / 21(0 \%)$ & $3 / 21(14.3 \%)$ & $18 / 21(85.7 \%)$ & - & • \\
\hline & Alimoglu & $\begin{array}{l}50.34 \\
(72.12 \pm 20.68) \\
-30.2 \%\end{array}$ & $\begin{array}{l}0.5,1,2,4 \\
\text { and } 8\end{array}$ & $11 / 58(19.0 \%)$ & $13 / 58(22.4 \%)$ & $32 / 58(55.2 \%)$ & $\bullet$ & $\bullet$ \\
\hline & Yang & $\begin{array}{l}75.77 \pm 21.66 \\
\quad(94.64 \pm 15.14) \\
-19.9 \%\end{array}$ & $0.5,1,2$ and 4 & $17 / 35(48.6 \%)$ & 口 & $18 / 35(51.4 \%)$ & $\bullet$ & $\bullet$ \\
\hline & Khater & $\begin{array}{l}28.1 \pm 8.7 \\
\quad(71.94 \pm 2.1) \\
-60.9 \%\end{array}$ & $0.5,1,2$ and 4 & $6 / 11(45.5 \%)$ & $3 / 11(27.3 \%)$ & $2 / 11(18.2 \%)$ & $\bullet$ & $\bullet$ \\
\hline & Liu & $\dot{23.9 \pm 2.6}$ & $\begin{array}{l}0.5,1,2,4 \\
\text { and } 8\end{array}$ & $\begin{array}{l}93 / 277 \\
(33.6 \%)\end{array}$ & $\begin{array}{l}88 / 277 \\
(31.8 \%)\end{array}$ & $\begin{array}{l}96 / 277 \\
(34.7 \%)\end{array}$ & $17.3 \pm 1.4$ & $23.9 \pm 2.6$ \\
\hline & Tasdoven & $\begin{array}{l}\text { 口 } \\
(80.7)\end{array}$ & $0.5,1,2$ and 4 & $14 / 63(22.2 \%)$ & $10 / 63(15.9 \%)$ & $39 / 63(61.9 \%)$ & - & 口 \\
\hline & Ajduk & $\begin{array}{l}\text { 口 } \\
(75.52 \pm 9.42)\end{array}$ & $\begin{array}{l}0.5,1,2,4 \\
\text { and } 8\end{array}$ & $\bullet$ & $\bullet$ & $\bullet$ & 口 & 口 \\
\hline & Callioglu & 0 & $\begin{array}{l}0.5,1,2,4 \\
\text { and } 8\end{array}$ & $\bullet$ & $\bullet$ & $\bullet$ & - & 曰 \\
\hline & Edizer & 0 & $\begin{array}{l}0.5,1,2,4 \\
\text { and } 8\end{array}$ & $22 / 48(45.7 \%)$ & $10 / 48(20.8 \%)$ & $16 / 48(33.3 \%)$ & $\bullet$ & $\bullet$ \\
\hline & Satar & $\begin{array}{l}52.5 \pm 28.4 \\
(82.2 \pm 18.7) \\
-36.13 \%\end{array}$ & $0.5,1$ and 2 & $\bullet$ & $\bullet$ & $\bullet$ & $\bullet$ & $\bullet$ \\
\hline & Aslan & $\begin{array}{l}50 \pm 19.6 \\
(70 \pm 17.8) \\
-28.57 \%\end{array}$ & $0.5,1,2$ and 4 & $\bullet$ & $\bullet$ & $\bullet$ & $\bullet$ & $\bullet$ \\
\hline & Narozny & $\begin{array}{l}50.62 \pm 2.16 \\
(65.4) \\
-22.60 \%\end{array}$ & $0.5,1$ and 2 & $\bullet$ & $\bullet$ & $\bullet$ & $\bullet$ & $\bullet$ \\
\hline & Chi & 0 & $\begin{array}{l}0.5,1,2,4 \\
\text { and } 8\end{array}$ & $3 / 30(10 \%)$ & $11 / 30(36.7 \%)$ & $16 / 30(53.3 \%)$ & $\bullet$ & $\bullet$ \\
\hline \multirow[t]{4}{*}{$\begin{array}{c}+ \text { Hyperbaric } \\
\mathrm{O}_{2}\end{array}$} & Cekin & $\begin{array}{l}41.75 \\
(81.47) \\
-48.8 \%\end{array}$ & $\bullet$ & $21 / 36(58.3 \%)$ & $8 / 36(22.2 \%)$ & $7 / 36(19.4 \%)$ & $\bullet$ & $\bullet$ \\
\hline & Topuz* & $\begin{array}{l}37.1 \\
(70.4) \\
-48.6 \%\end{array}$ & $0.5,1,2$ and 4 & $\bullet$ & $\bullet$ & $\bullet$ & $22.53 \pm 12.68$ & $35.45 \pm 22.09$ \\
\hline & Fujimura* & $\begin{array}{l}64.4 \pm 2.7 \\
(74.7 \pm 2.3) \\
-13.8 \%\end{array}$ & $0.5,1,2$ and 4 & $12 / 67(17.9 \%)$ & $40 / 67(59.7 \%)$ & $15 / 67(22.4 \%)$ & • & • \\
\hline & Pezzoli* & $\begin{array}{l}56.7 \pm 15.3 \\
\quad(72.3 \pm 27.6) \\
-21.6 \%\end{array}$ & $\begin{array}{l}0.5,1,2,4,6 \\
\quad \text { and } 8\end{array}$ & $1 / 23(4.3 \%)$ & $5 / 23(21.7 \%)$ & $17 / 23(73.9 \%)$ & 口 & 口 \\
\hline
\end{tabular}


Table 1 (continued)

\begin{tabular}{|c|c|c|c|c|c|c|c|c|}
\hline Intervention & Study & $\begin{array}{l}\text { PTA }(\mathrm{dB})(\mathrm{SD} / \\
\text { IRQ }) \\
\text { (PTA at baseline) } \\
(\Delta \%)\end{array}$ & $\begin{array}{l}\text { PTA level } \\
(\mathrm{kHz})\end{array}$ & $\begin{array}{l}\text { Complete } \\
\text { hearing } \\
\text { improvement } \\
(\%)^{*}\end{array}$ & $\begin{array}{l}\text { Moder- } \\
\text { ate hearing } \\
\text { improvement } \\
(\%)^{*}\end{array}$ & $\begin{array}{l}\text { No hearing } \\
\text { improvement } \\
(\%)^{*}\end{array}$ & $\begin{array}{l}\text { Mean hear- } \\
\text { ing gain }<60 \\
\mathrm{~dB}\end{array}$ & $\begin{array}{l}\text { Mean hear- } \\
\text { ing gain }>61 \\
\mathrm{~dB}\end{array}$ \\
\hline & Alimoglu* & $\begin{array}{l}36.85 \\
(63.68 \pm 22.97) \\
-42.1 \%\end{array}$ & $\begin{array}{l}0.5,1,2,4 \\
\text { and } 8\end{array}$ & $26 / 61(42.6 \%)$ & $14 / 61(22.9 \%)$ & $21 / 61(34.4 \%)$ & $\bullet$ & $\bullet$ \\
\hline & Yang & $\begin{array}{l}74.76 \pm 18.7 \\
\quad(97.26 \pm 15.1) \\
-23.1 \%\end{array}$ & $0.5,1,2$ and 4 & $13 / 19(68.4 \%)$ & 口 & $6 / 19(31.6 \%)$ & $\bullet$ & $\bullet$ \\
\hline & Khater* & $\begin{array}{l}18.1 \pm 2.2 \\
(72.86 \pm 1.43) \\
-75.15 \%\end{array}$ & $0.5,1,2$ and 4 & $8 / 11(72.7 \%)$ & $2 / 11(18.2 \%)$ & $1 / 11(9.1 \%)$ & $\bullet$ & $\bullet$ \\
\hline & Liu & $\begin{array}{l}\bullet \\
(22.7 \pm 3.9)\end{array}$ & $\begin{array}{l}0.5,1,2,4 \\
\text { and } 8\end{array}$ & $\begin{array}{l}17 / 112 \\
(15.2 \%)\end{array}$ & $56 / 112(50 \%)$ & $\begin{array}{l}39 / 112 \\
(34.8 \%)\end{array}$ & $9.9 \pm 2.2$ & $22.7 \pm 3.9$ \\
\hline & Tasdoven & $\begin{array}{l}\text { 口 } \\
(92.02)\end{array}$ & $0.5,1,2$ and 4 & $3 / 26(11.5 \%)$ & $4 / 26(15.4 \%)$ & $19 / 26(73.1 \%)$ & 0 & 口 \\
\hline & Ajduk & $\begin{array}{l}\text { 口 } \\
(80.57 \pm 5.14)\end{array}$ & $\begin{array}{l}0.5,1,2,4 \\
\text { and } 8\end{array}$ & $\bullet$ & $\bullet$ & $\bullet$ & 口 & • \\
\hline & Callioglu & 口 & $\begin{array}{l}0.5,1,2,4 \\
\text { and } 8\end{array}$ & $\bullet$ & $\bullet$ & $\bullet$ & - & 口 \\
\hline & Edizer & 口 & $\begin{array}{l}0.5,1,2,4 \\
\text { and } 8\end{array}$ & $13 / 53(24.4 \%)$ & $16 / 53(30.1 \%)$ & $24 / 53(45.2 \%)$ & $\bullet$ & $\bullet$ \\
\hline & Satar & $\begin{array}{l}48.5 \pm 32.1 \\
(68.1 \pm 24.4) \\
-28.78 \%\end{array}$ & $0.5,1$ and 2 & $\bullet$ & $\bullet$ & $\bullet$ & $\bullet$ & $\bullet$ \\
\hline & Aslan* & $\begin{array}{l}30.1 \pm 24.0 \\
(68 \pm 19.3) \\
-55.74 \%\end{array}$ & $0.5,1,2$ and 4 & $\bullet$ & $\bullet$ & $\bullet$ & $\bullet$ & $\bullet$ \\
\hline & Narozny* & $\begin{array}{l}30.72 \pm 2.70 \\
(58.2) \\
-47.22 \%\end{array}$ & $0.5,1$ and 2 & $\bullet$ & $\bullet$ & $\bullet$ & $\bullet$ & $\bullet$ \\
\hline & Chi* & 口 & $\begin{array}{l}0.5,1,2,4 \\
\text { and } 8\end{array}$ & $8 / 30(26.7 \%)$ & $16 / 30(53.3 \%)$ & $6 / 30(20 \%)$ & $\bullet$ & $\bullet$ \\
\hline
\end{tabular}

- not conducted, $\boldsymbol{\square}$ not extractable, $P T A$ pure-tone average $(\mathrm{kHz})$, no. participants/total participants $(\%), I R Q$ interquartile range

*Statistically significant difference $(p<0.05)$

\section{Results}

\section{Search results and selection process}

Figure 1 summarizes the study selection process in a flowchart. We retrieved a total of 182 articles. After title and abstract screening, 34 articles were assessed in full text. In total, 16 articles were included in this systematic review [15-30].

\section{Quality assessment}

According to the RoBANS, the risk of bias of the articles was independently appraised by two reviewers. All eligible articles had satisfactory quality therefore were included for data extraction. Table 2 shows the results of the quality assessment [15-30].

\section{Baseline characteristics}

The total number of operated ears was 1759 of whom 580 were treated with HBO (Table 2). Three different methods of administration were applied. The most performed procedure was the systemic administration for 1278 ears. An intratympanic route was administered for 356 ears. Intravenous was established for 125 ears. Follow-up time varied between 3 weeks and 72 months. 2 out of 16 studies treated their patients with HBO therapy after failure of conventional treatment in ISSHL.

\section{Systemic steroids with hyperbaric oxygen therapy}

Ten suitable trials involving 1295 patients were retrieved (Table 3) [17-25]. A study conducted by Topuz et al., demonstrated an average of the hearing gain at five contiguous 
Fig. 1 PRISMA flowchart

frequencies significantly higher in the $\mathrm{HBO}+\mathrm{SS}$ group for patients with severe or profound hearing impairment (respectively, $p=0.014$ and $p=0.005$ ) [15]. The same result was obtained in the trial guided by Fujimura et al. [16]. Patients suffering from profound hearing loss demonstrated a significantly higher improvement rate in the HBO group than the steroid group $(p<0.05)$.

Tasdoven et al. conducted a trial which indicated that there was no significant difference in the response to treatment between the intervention and control group $(p<0.355)$ [17]. However, they found a statistically significant difference in patients who suffered from profound hearing loss. ( $p=0.012)$ A different trial, had the same conclusion with regard to the significance of HBO therapy on patients with severe/profound hearing loss (Table 3) [18].

Three studies, conluded that the addition of HBO did not have a significant impact on the prognosis [19-21]. Satar et al. found a hearing gain in favour of the HBO group. However, this difference was not significant $(p=0.754)$ [22]. In three studies, a significant improvement was found after the addition of HBO therapy [23-25].

\section{Intravenous steroids with hyperbaric oxygen therapy}

Pezzoli et al., assessed 44 patients with ISSHL in their clinical trial [26]. Mean PTA gain was significantly better in the intervention group compared to controls $(p=0.01)$. Recovery for patients suffering from profound and severe hearing loss was significantly associated with a therapy form based upon HBO + IVS $(p=0.046)$.

In Pezzoli's study, having experienced a moderate form of hearing impairment and increasing days after onset were negatively correlated with recovery. In Alimoglu et al., subjects whom received combination therapy in the first 15 days after onset, showed a statistically significant difference between mean gains $(p<0.05)$ [27].

Ajduk et al. proposed that patients with an initial hearing loss of $\leq 60 \mathrm{~dB}$ had significant improvement at $500 \mathrm{~Hz}$ [28] Whereas subjects with severe/profound hearing impairment had significant improvements at all six frequencies after they were treated with a combination of IVS + HBO. 
Table 2 Critical appraisal

\begin{tabular}{|c|c|c|c|c|c|c|c|c|c|}
\hline Study & $\begin{array}{l}\text { Publication } \\
\text { year }\end{array}$ & Study design & Participants & $\begin{array}{l}\text { Selection of } \\
\text { participants }\end{array}$ & $\begin{array}{l}\text { Confound- } \\
\text { ing vari- } \\
\text { ables }\end{array}$ & $\begin{array}{l}\text { Intervention } \\
\text { measurement }\end{array}$ & $\begin{array}{l}\text { Blinding } \\
\text { of outcome } \\
\text { assessment }\end{array}$ & $\begin{array}{l}\text { Incomplete } \\
\text { outcome } \\
\text { data }\end{array}$ & $\begin{array}{l}\text { Selective } \\
\text { outcome } \\
\text { reporting }\end{array}$ \\
\hline Cekin & 2009 & RCT & 57 & $\mathrm{~L}$ & $\mathrm{H}$ & $\mathrm{U}$ & $\mathrm{U}$ & $\mathrm{H}$ & $\mathrm{L}$ \\
\hline Topuz & 2003 & RCET & 51 & $\mathrm{~L}$ & $\mathrm{~L}$ & $\mathrm{~L}$ & $\mathrm{U}$ & $\mathrm{L}$ & $\mathrm{L}$ \\
\hline Fujimura & 2007 & RCS & 130 & $\mathrm{H}$ & $\mathrm{U}$ & $\mathrm{L}$ & $\mathrm{H}$ & $\mathrm{L}$ & $\mathrm{L}$ \\
\hline Pezzoli & 2015 & PCS & 44 & $\mathrm{H}$ & $\mathrm{L}$ & $\mathrm{U}$ & $\mathrm{L}$ & $\mathrm{L}$ & $\mathrm{L}$ \\
\hline Alimoglu & 2011 & RCR & 219 & $\mathrm{H}$ & $\mathrm{L}$ & $\mathrm{L}$ & $\mathrm{U}$ & $\mathrm{H}$ & $\mathrm{H}$ \\
\hline Yang & 2013 & RCS & 103 & $\mathrm{H}$ & $\mathrm{L}$ & $\mathrm{H}$ & $\mathrm{H}$ & $\mathrm{L}$ & $\mathrm{L}$ \\
\hline Khater & 2016 & PCS & 22 & $\mathrm{H}$ & $\mathrm{L}$ & $\mathrm{U}$ & $\mathrm{U}$ & $\mathrm{L}$ & $\mathrm{L}$ \\
\hline Tasdöven & 2016 & RCS & 89 & $\mathrm{H}$ & $\mathrm{U}$ & $\mathrm{L}$ & $\mathrm{U}$ & $\mathrm{H}$ & $\mathrm{L}$ \\
\hline Ajduk & 2017 & RCS & 93 & $\mathrm{H}$ & $\mathrm{H}$ & $\mathrm{U}$ & $\mathrm{L}$ & $\mathrm{L}$ & $\mathrm{L}$ \\
\hline Callioglu & 2015 & RCS & 44 & $\mathrm{H}$ & $\mathrm{H}$ & $\mathrm{L}$ & $\mathrm{U}$ & $\mathrm{H}$ & $\mathrm{L}$ \\
\hline Liu & 2011 & RCS & 465 & $\mathrm{H}$ & $\mathrm{L}$ & $\mathrm{U}$ & $\mathrm{H}$ & $\mathrm{L}$ & $\mathrm{L}$ \\
\hline Edizer & 2015 & RCS & 205 & $\mathrm{H}$ & $\mathrm{H}$ & $\mathrm{L}$ & $\mathrm{L}$ & $\mathrm{H}$ & $\mathrm{L}$ \\
\hline Satar & 2006 & RCS & 54 & $\mathrm{H}$ & $\mathrm{U}$ & $\mathrm{H}$ & $\mathrm{L}$ & $\mathrm{L}$ & $\mathrm{H}$ \\
\hline Aslan & 2002 & RCS & 50 & $\mathrm{H}$ & $\mathrm{H}$ & $\mathrm{L}$ & $\mathrm{U}$ & $\mathrm{L}$ & $\mathrm{L}$ \\
\hline Narozny & 2004 & RCS & 133 & $\mathrm{H}$ & $\mathrm{L}$ & $\mathrm{H}$ & $\mathrm{H}$ & $\mathrm{L}$ & $\mathrm{L}$ \\
\hline Chi & 2017 & RCT & 60 & $\mathrm{~L}$ & $\mathrm{~L}$ & $\mathrm{~L}$ & $\mathrm{U}$ & $\mathrm{L}$ & $\mathrm{L}$ \\
\hline
\end{tabular}

Study first author of the published study, Publication year year of publication, Study design RCS Retrospective Cohort Study, PCS Prospective Cohort Study, RCET Randomized Comparison Effectiveness Trial, RCT Randomized Clinical Trial, RCR Retrospective Case Review, Participants number of included relevant participants, Selection of participants selection bias caused by inadequate selection of participants, Confounding variables selection bias caused by inadequate confirmation and consideration of confounding variable, Intervention measurement performance bias caused by inadequate measurement of intervention, Blinding of outcome assessment detection bias caused by inadequate blinding of outcome assessment, Incomplete outcome data attrition bias caused by inadequate handling of incomplete outcome data, Selective outcome reporting reporting bias caused by selective outcome reporting, $L$ low, $H$ high, $U$ unclear

\section{Intratympanic steroid injections with hyperbaric oxygen therapy}

Khater et al., treated 22 patients who suffered from ISSHL [29]. The patients were randomly assigned into two groups. The HBO treated group performed significantly better than the ITS group $(p=0.0014)$.

A clinical trial conducted by Chao et al. compared the usage of ITS in combination with HBO therapy [30]. The hearing gain in the ITS + HBO group $(22.5 \pm 18.7 \mathrm{~dB})$ was greater than in the ITS group $(18.87 \pm 21.66 \mathrm{~dB})$; however, there was no statistical significant difference between both groups $(p>0.05)$.

\section{Discussion}

In this systematic review, we executed a search of the literature to identify evidence evaluating the effectiveness of hyperbaric oxygen therapy in ISSHL. Our search identified a total of 16 articles [15-30]. In all these articles, treatment groups were separated according to HBO therapy. This additive treatment was applied next to the conventional intervention, namely steroid medication (either intravenous, oral, intratympanic or a combination of these).

\section{Disease onset and timing of treatment}

Various outcomes regarding the effectiveness of HBO are reported: eight out of sixteen articles, concluded that there was a significant difference between the intervention and control group [15, 16, 23-27, 29]. The rationale behind hyperbaric oxygen treatment lies in its vasodilatative effect on the organ of Corti and other inner ear structures (such as the stria vascularis) thereby countering the vascular compromise and oxidative stress which are hypothesized to be major factors playing a role in sustaining ISSHL [31]. This might therefore result in a cumulative treatment effect next to the reduction of inflammation by steroid application. The next relevant clinical question is raised regarding the duration of this destructive inflammatory, vasoconstrictive period directly after disease onset by a yet unknown factor (viral, auto-immune): is there a maximum interval after disease onset within which treatment is useful and effective? International guidelines agree on start of steroid treatment (within $72 \mathrm{~h}$ ) [32]. In this review, no concordance in start of HBO therapy after disease onset could be found. Most of the effects (if any) are to be expected as soon as possible after symptoms arise. The effectiveness of HBO is timedependent and effectivity decreases with increasing delay in administration [33]. According to Edizer et al., the rate of 


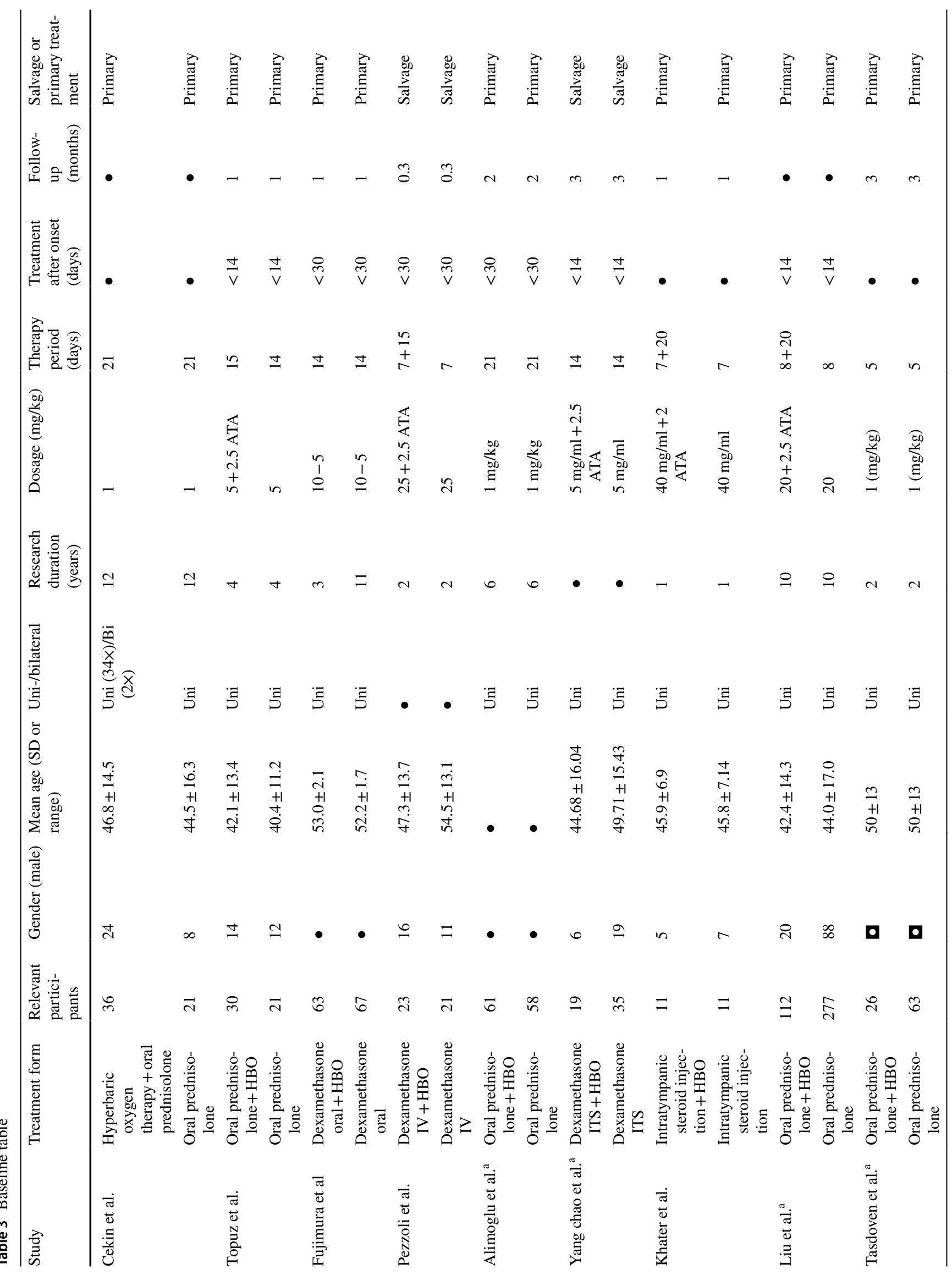




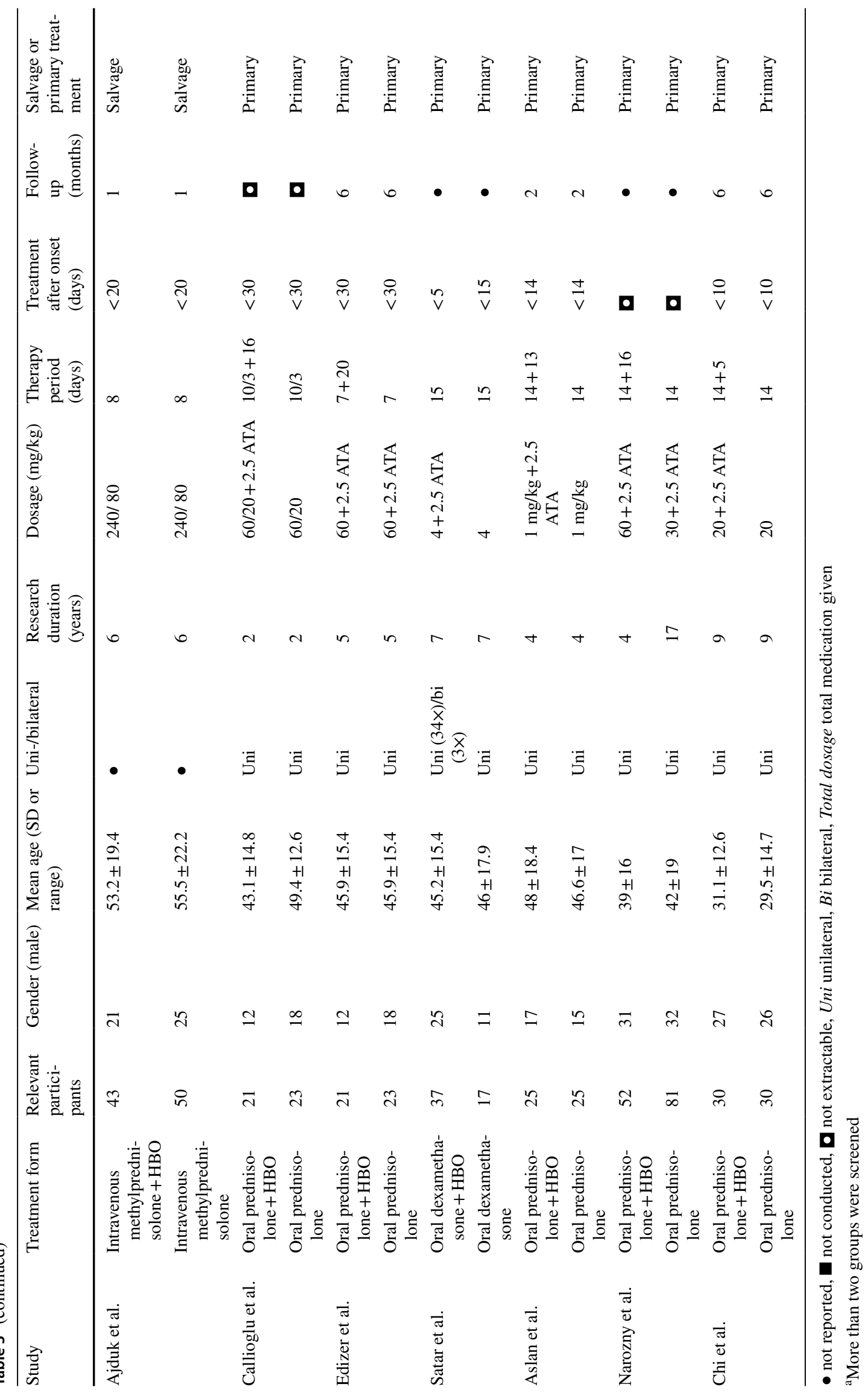


no recovery was significantly higher in patients who started treatment after 10 days of onset $(p=0.010)$. The same negative correlation has been recognised by various other reports [34-38].

Though early application of HBOT appears to be a logical advice, practical burden arises. Are there HBO therapy centers available in the region and are these capable of accepting this 'new patient flow' for a new indication (hearing recovery after ISSHL). And if so, is it cost effective? There is a considerable percentage of patients known to recover spontaneously [4]. This review study has shown evidence that mainly severe to profound ISSHL demonstrate more hearing recovery than moderate or mild. Therefore, a selection in the patient presentation seems advisable to attain this effect. Future randomized controlled trials are advocated to further illuminate these findings before drawing any conclusions regarding $\mathrm{HBO}$ effectiveness as an additive treatment. Hyperbaric oxygen chambers are mostly available in specialised hospitals. Also, the costs of hyperbaric treatment modalities have to be taken into account. A facility in Australia calculated that the cost of one HBO session would be around 304 Australian Dollars [39].

\section{Pathophysiology ISSHL and rationale HBOT}

There is a significant higher impact of the combination therapy (SS + HBO) on ISSHL patients diagnosed with severe or profound hearing loss. Various studies have shown the hearing recovery in this specific category of patients [15-21, 23-30]. In a study conducted by Topuz et al., the intervention group had a statistical significant difference in comparison to the control group in patients with initial hearing loss levels of $61-80$ and $\geq 81 \mathrm{~dB}$ ( $p=0.014$ and $p=0.005$,respectively) [15]. These results (amongst others) insinuate that the addition of HBO might be of benefit in cases of severe and profound hearing impairment. One might postulate that in these patients, the oxidative stress (as is mentioned before) is more elevated (and therefore damage to inner ear structures such as organ of Corti with its inner/outer hair cells), in comparison to the other groups and therefore explain the more successful outcome when HBO therapy is added to the treatment regimen. Therefore, our hypothesis finds support in that early treatment might be primordial to treat the damage (in parallel with patients after exposure to loud noise or ototoxic agents). However, no concordant evidence is available in the literature to support this.

Lamm et al., suggested HBO therapy as an adjuvant form of treatment after failure of conventional therapy in ISSHL [33]. Nonetheless, using HBO therapy as a primary treatment seems to cause less effect in comparison to the usage of steroids [27]. Various reports have indicated that the utilisation of $\mathrm{HBO}$ as a "last resort" remedy can cause significant improvement of hearing thresholds [33, 40-43].
The impact of spontaneous recovery should be taken into consideration while assessing the impact of $\mathrm{HBO}$ as a form of "salvage" therapy. According to Mattox, 29-78\% of the ISSHL patients recover spontaneously in their first 2 weeks after onset [4]. A number of determinants influence the prospect of spontaneous recovery, these include degree of hearing loss, patient age, vertigo and time between onset of hearing loss and treatment [44].

\section{Safety and complication rate of HBOT}

$\mathrm{HBO}$ is recognised as a safe treatment modality if the pressure is kept lower than three atmospheres (ATM) with sessions lasting up to $2 \mathrm{~h}$ [45]. A study conducted by Hadanny included 2334 patients with a total of 62,614 hyperbaric sessions [46]. 406 of the 2334 patients (17.4\%) experienced one or more complications during their HBO sessions. with an overall per-session incidence of $721: 100,000$ events $(0.72 \%)$. The complications did not cause any harm on a longer timeframe. Most patients endured barotrauma as a complication after initiation of the therapy. Strict protocols, such as inchamber monitoring have to be established to ensure the safety of patients [46].

\section{Limitations}

HBOT was given to patients with ISSHL next to steroid medication (either systemic, local or a combination of these). The variation in steroid regimen, method of administration and therapy duration differed distinctively among the studies. Also, the patients were not pooled correctly in some cases. These distinctions could potentially influence the comparability of various study cases and cause confounding bias. Though little is known about the final treatment outcome between the various application methods, it is highly unlikely the application method will interfere with hearing outcome [47]. Most of the included studies did not attest as qualitative articles. The applied guidelines for the distinction between profound and moderate ISSHL, demonstrated a notable difference. Whereas, the reports of audiometric outcomes showed some discrepancy with regards to the meaning of a $20 \mathrm{~dB}$ recovery for moderate ISSHL and severe to profound ISSHL. The limitations mentioned in this systematic review should be considered when evaluating its outcomes.

\section{Conclusion}

In general, there was no significant difference observed between the intervention and control group. However, in severe to profound hearing loss, according to some reports, the patients might benefit from the adjunction of $\mathrm{HBO}$ to 
corticotherapy. Future prospective research, with larger series is required to further illuminate this topic.

Funding None.

\section{Compliance with ethical standards}

Conflict of interest The authors declare no conflict of interest.

Open Access This article is distributed under the terms of the Creative Commons Attribution 4.0 International License (http://creativeco mmons.org/licenses/by/4.0/), which permits unrestricted use, distribution, and reproduction in any medium, provided you give appropriate credit to the original author(s) and the source, provide a link to the Creative Commons license, and indicate if changes were made.

\section{Appendix 1: Search strategy}

\begin{tabular}{ll}
\hline Database & Search-19 May 2018 \\
\hline Pubmed & $((((((($ hearing loss, \\
& sensorineural[MeSH Terms]) \\
OR hearing loss, sudden[MeSH \\
Terms]) OR sudden \\
deafness[MeSH Terms]) OR \\
hearing impairment[MeSH \\
Terms]) OR idiopathic sudden \\
sensorineural hearing loss[Title/ \\
Abstract]) OR sensorineural \\
hearing loss[Title/Abstract])) \\
AND ((((Oxygen Therapy, \\
Hyperbaric[MeSH Terms]) \\
OR Oxygen Therapies, \\
Hyperbaric[MeSH Terms]) OR \\
Hyperbaric Oxygenations[Title/ \\
Abstract]) OR HBO[Title/ \\
Abstract]) OR hyperbaric[Title/ \\
Abstract]) AND \\
(((((steroid*[MeSH Terms]) OR \\
glucorticoid[MeSH Terms]) OR \\
prednison*[MeSH Terms]) OR \\
corticosteroids[MeSH Terms]) \\
OR dexamethasone[Title/ \\
Abstract]) OR deltasone[Title/ \\
Abstract]) \\
\hline
\end{tabular}

\begin{tabular}{|c|c|}
\hline Database & Search—19 May 2018 \\
\hline Embase & $\begin{array}{l}\text { sensorineural hearing } \\
\text { loss':ti,ab,kw OR 'sudden } \\
\text { hearing loss':ti,ab,kw OR } \\
\text { 'sudden deafness':ti,ab,kw OR } \\
\text { 'hearing impairment':ti,ab,kw } \\
\text { OR 'idiopathic sud- } \\
\text { den sensorineural hearing } \\
\text { loss':ti,ab,kw AND hyperbarc } \\
\text { oxygen therapy':ti,ab,kw } \\
\text { OR 'hyperbaric oxygen } \\
\text { therapies':ti,ab,kw OR 'hyper- } \\
\text { baric oxygenations':ti,ab,kw } \\
\text { OR 'hbo':ti,ab,kw OR } \\
\text { 'hyperbaric':ti,ab,kw AND } \\
\text { steroid*':ti,ab,kw OR } \\
\text { 'glucocorticoid*':ti,ab,kw } \\
\text { OR 'prednisone':ti,ab,kw OR } \\
\text { 'corticosteroid':ti,ab,kw OR } \\
\text { 'dexamethasone':ti,ab,kw }\end{array}$ \\
\hline Cochrane & 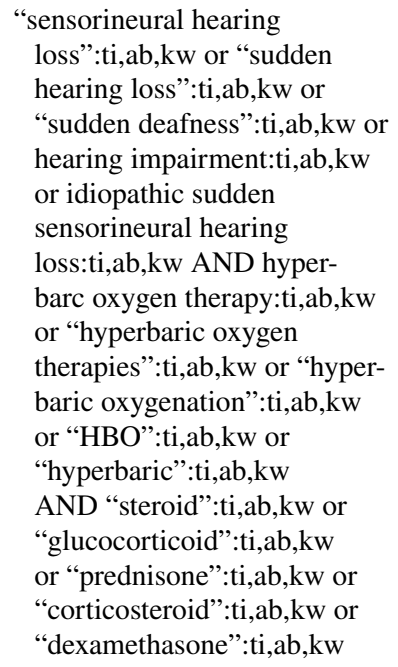 \\
\hline
\end{tabular}

\section{References}

1. National Institute of Health (2000) Sudden deafness. National Institutes of Health NIH publication, Bethesda, p 4757

2. Byl FM Jr (1984) Sudden hearing loss: eight years' experience and suggested prognostic table. Laryngoscope 94:647-661

3. Hughes GB (1998) Sudden hearing loss. In: Gates GA (ed) Current herapy in otolaryngology-head and neck surgery, 6th edn. Mosby, St. Louis, p 41

4. Mattox DE, Simmons FB (1977) Natural history of sudden sensorineural hearing loss. Ann Otol Rhinol Laryngol 86:463-480

5. Ho HG, Lin HC, Shu MT, Yang CC, Tsai HT (2004) Effectiveness of intratympanic dexamethasone injection in sudden- deafness patients as salvage treatment. Laryngoscope 114:1184-1189

6. Goto F, Fujita T, Kitani Y, Kanno M, Kamei T, Ishii H (1979) Hyperbaric oxygen and stellate ganglion blocks for idiopathic sudden hearing loss. Acta Otolaryngol 88:335-342

7. Vincey P (1978) Application and use of hyperbaric oxygenation in E.N.T. Rev Laryngol Otol Rhinol. (Bord) 99:619-634 
8. Lamm K, Lamm C, Arnold W (1998) Effect of isobaric oxygen versus hyperbaric oxygen on the normal and noise-damaged hypoxic and ischemic guinea pig inner ear. Adv Otorhinolaryngol 54:59-85

9. Moher D, Liberati A, Tetzlaff J, Altman DG, Group P (2009) Preferred reporting items for systematic reviews and meta-analyses: the PRISMA statement. Bmj 339:b2535

10. Liberati A, Altman DG, Tetzlaff J et al (2009) The PRISMA statement for reporting systematic reviews and meta-analyses of studies that evaluate healthcare interventions: explanation and elaboration. Bmj 339:b2700

11. Kim SY, Park JE, Lee YJ et al (2013) Testing a tool for assessing the risk of bias for nonrandomized studies showed moderate reliability and promising validity. J Clin Epidemiol 66(4):408-414

12. Committee on Hearing and Equilibrium (1995) Guidelines for the diagnosis and evaluation of therapy in Menière's disease. Otolaryngol Head Neck Surg 113:181-185

13. Siegel LG (1975) The treatment of idiopathic sudden sensorineural hearing loss. Otolaryngol Clin N Am 8:467-473

14. World Health Organisation (2018) Prevention of blindness and deafness-grades of hearing impairment. http://www.who.int/ $\mathrm{pbd} /$ deafness/hearing_impairment_grades/en/. Accesed 15 Jan 2018

15. Topuz E, Yigit O, Cinar U, Seven H (2003) Should hyperbaric oxygen be added to treatment in idiopathic sudden sensorineural hearing loss? Eur Arch Oto Rhino Laryngol. https://doi. org/10.1007/s00405-003-0688-6

16. Fujimura T, Suzuki H, Shiomori T, Udaka T, Mori T (2007) Hyperbaric oxygen and steroid therapy for idiopathic sudden sensorineural hearing loss. Eur Arch Otorhinolaryngol 264(8):861866. https://doi.org/10.1007/s00405-007-0272-6

17. Taşdöven GE, Derin AT, Yaprak N, Özçağlar H (2017) The place of hyperbaric oxygen therapy and ozone therapy in sudden hearing loss. Braz J Otorhinolaryngol 83(4):457-463. https://doi. org/10.1016/j.bjorl.2016.06.002

18. Liu S, Kang B, Lee J, Lin Y, Huang K, Liu D, Wang C (2011) Comparison of therapeutic results in sudden sensorineural hearing loss with/without additional hyperbaric oxygen therapy: a retrospective review of 465 audiologically controlled cases. Clin Otolaryngol 36(2):121-128. https://doi.org/10.111 1/j.1749-4486.2011.02303.x

19. Çekin E, Cincik H, Ulubil SA, Gungor A (2009) Effectiveness of hyperbaric oxygen therapy in management of sudden hearing loss. J Laryngol Otol 123(06):609. https://doi.org/10.1017/s002221510 9004277

20. Edizer DT et al (2015) Recovery of idiopathic sudden sensorineural hearing loss. J Int Adv Otol 11(2):122-126

21. Ersoy Callioglu E, Tuzuner A, Demirci S, Cengiz C, Caylan R (2015) Comparison of simultaneous systemic steroid and hyperbaric oxygen treatment versus only steroid in idiopathic sudden sensorineural hearing loss. Int J Clin Exp Med 8:9876-9882

22. Satar B, Hidir Y, Yetiser S (2006) Effectiveness of hyperbaric oxygen therapy in idiopathic sudden hearing loss. J Laryngol Otol 120:665-669

23. Aslan I, Oysu C, Veyseller B, Baserer N (2002) Does the addition of hyperbaric oxygen therapy to the conventional treatment modalities influence the outcome of sudden deafness? Otolaryngol Head Neck Surg 126(2):121-126

24. Narozny W, Sicko Z, Przewozny T, Stankiewicz C, Kot J, Kuczkowski J (2004 Nov) Usefulness of high doses of glucocorticoids and hyperbaric oxygen therapy in sudden sensorineural hearing loss treatment. Otol Neurotol 25(6):916-923

25. Chi TH, Chiang MC, Chen RF, Yuan CH (2018) Does the addition of hyperbaric oxygen therapy to conventional treatment modalities influence the outcome of soldiers with idiopathic sudden sensorineural hearing loss? J R Army Med Corps. https://doi. org/10.1136/jramc-2017-000872

26. Pezzoli M, Magnano M, Maffi L, Pezzoli L, Marcato P, Orione M, Bongioannini G (2014) Hyperbaric oxygen therapy as salvage treatment for sudden sensorineural hearing loss: a prospective controlled study. Eur Arch Otorhinolaryngol 272(7):1659-1666. https://doi.org/10.1007/s00405-014-2948-z

27. Alimoglu Y, Inci E, Edizer DT, Ozdilek A, Aslan M (2011) Efficacy comparison of oral steroid, intratympanic steroid, hyperbaric oxygen and oral steroid hyperbaric oxygen treatments in idiopathic sudden sensorineural hearing loss cases. Eur Arch Otorhinolaryngol 268(12):1735-1741. https://doi.org/10.1007/ s00405-011-1563-5

28. Ajduk J, Ries M, Trotic R, Marinac I, Vlatka K, Bedekovic V (2017) Hyperbaric oxygen therapy as salvage therapy for sudden sensorineural hearing loss. J Int Adv Otol 13(1):61-64. https:// doi.org/10.5152/iao.2017.3185

29. Elbahrawy A, Khater A, El-Anwar M, Nofal A (2017) Sudden sensorineural hearing loss: comparative study of different treatment modalities. Int Arch Otorhinolaryngol. https://doi. org/10.1055/s-0037-1605376

30. Yang C, Wu R, Hwang C (2013) Comparison of intratympanic steroid injection, hyperbaric oxygen and combination therapy in refractory sudden sensorineural hearing loss. Otol Neurotol 34(8):1411-1416. https://doi.org/10.1097/mao.0b013e3182a1eb8 3

31. Merchant SN, Adams JC, Nadol JB (2005) Pathology and pathophysiology of idiopathic sudden sensorineural hearing loss. Otol Neurotol 26(2):151-160. https://doi.org/10.1097/00129492-20050 3000-00004

32. Stachler RJ, Chandrasekar SS, Archer SM et al (2012) Clinical practice guideline: sudden hearing loss. Otolaryngol Head Neck Surg 146:S1

33. Lamm K, Lamm H, Arnold W (1998) Effect of hyperbaric oxygen therapy in comparison to conventional or placebo therapy or no treatment in idiopathic sudden hearing loss, acoustic trauma, noise-induced hearing loss and tinnitus: a literature survey. Adv Otorhinolaryngol 54:86-99

34. Ceylan A, Celenk F, Kemaloğlu YK, Bayazit YA, Göksu N, Ozbilen S (2007) Impact of prognostic factors on recovery from sudden hearing loss. J Laryngol Otol 121:1035-1040

35. Cvorović L, Deric D, Probst R, Hegemann S (2008) Prognostic model for predicting hearing recovery in idiopathic sudden sensorineural hearing loss. Otol Neurotol 29:464-469

36. Nosrati-Zarenoe R, Hultcrantz E (2012) Corticosteroid treatment of idiopathic sudden sensorineural hearing loss: randomized triple-blind placebo-controlled trial. Otol Neurotol 33:523-531

37. Wang CT, Huang TW, Kuo SW, Cheng PW (2009) Correlation between audiovestibular function tests and hearing outcomes in severe to profound sudden sensorineural hearing loss. Ear Hear 30:110-114

38. Cho CS, Choi YJ (2013) Prognostic factors in sudden sensorineural hearing loss: a retrospective study using interaction effects. Braz J Otorhinolaryngol 79:466-470

39. Gomez-Castillo JD, Bennett MH (2005) The cost of hyperbaric therapy at the Prince of Wales Hospital, Sydney. S Pac Underw Med Soc J 35:194-198

40. Muzzi E, Zennaro B, Visentin R, Soldano F, Sacilotto C (2010) Hyperbaric oxygen therapy as salvage treatment for sudden sensorineural hearing loss: review of rationale and preliminary report. J Laryngol Otol 124:e2

41. Horn CE, Himel HN, Selesnick SH (2005) Hyperbaric oxygen therapy for sudden sensorineural hearing loss: a prospective trial of patients failing steroid and antiviral treatment. Otol Neurotol $26: 882-889$ 
42. Desloovere C, Knecht R, Germonpré P (2006) Hyperbaric oxygen therapy after failure of conventional therapy for sudden deaf- ness. B-ENT 2:69-73

43. Körpinar S, Alkan Z, Yiğit O, Gör AP, Toklu AS, Cakir B, Soyuyüce OG, Ozkul H (2011) Factors influencing the outcome of idiopathic sudden sensorineural hearing loss treated with hyperbaric oxygen therapy. Eur Arch Otorhinolaryngol 268:41-47

44. Rauch SD (2008) Clinical practice. Idiopathic sudden sensorineural hearing loss. N Engl J Med 359:833-840
45. Le W (2008) Hyperbaric oxygen therapy indications. UHMS 12th edition:215-218

46. Hadanny A, Meir O, Bechor Y et al (2016) The safety of hyperbaric oxygen treatment-retrospective analysis in 2,334 patients. Undersea Hyperb Med 43(2):113-122

47. Martens EP (2007) Methods to adjust for confounding: propensity scores and instrumental variables. Doctoral thesis Utrecht, University of Utrecht, The Netherlands 